\title{
A retrospective clinical, radiographic and microbiological study of periodontal conditions of teeth with and without crowns
}

\author{
Um estudo retrospectivo clínico, radiográfico e \\ microbiológico das condições periodontais de \\ dentes com e sem coroas
}

\begin{abstract}
Marcio Dias Giollo(a) Patrícia Moura Valle(a) Sabrina Carvalho Gomes ${ }^{(a)}$ Cassiano Kuchenbecker Rösing ${ }^{(a)}$
\end{abstract}

(a) Professors of Prosthodontics, Lutheran University of Brazil, Porto Alegre, RS, Brazil.

\author{
Corresponding author: \\ Cassiano Kuchenbecker Rösing \\ Rua Dr. Valle, 433/801 \\ Porto Alegre - RS - Brazil \\ CEP: 90560-010 \\ E-mail: ckrosing@hotmail.com
}

Received for publication on Jul 26, 2006 Sent for alterations on Jan 19, 2007 Accepted for publication on Mar 05, 2007
Abstract: The aim of this study was to evaluate retrospectively the periodontal conditions of teeth with fixed crowns that had been in place from 3 to 5 years before the study was conducted. Forty individuals were recalled for a follow-up visit. Full-mouth clinical examinations were carried out and Visible Plaque Index (VPI), Gingival Bleeding Index (GBI), Probing Pocket Depth (PPD), and clinical attachment level (CAL) were assessed in 6 sites per tooth. Parallel radiographs were also taken and blindly analyzed by a digital caliper (distance between the apex and the bone crest). BANA tests were performed. A contralateral sound tooth was considered the control. Mean values were obtained and Wilcoxon and paired sample $t$ tests were used to compare the test and control sites. Crowns had a mean VPI value of $30.42 \%$ as compared to $49.17 \%$ for sound teeth. The GBI was $33.33 \%$ and $26.25 \%$ for test and control teeth respectively. Assessment of PPD revealed values of 2.30 and $2.14 \mathrm{~mm}$, and assessment of CAL revealed averages of 2.02 and $1.89 \mathrm{~mm}$ for test and control teeth respectively. The mean values for radiographic distances were 12.73 and $13.67 \mathrm{~mm}$, and for the BANA test, 67.50 and 50.00 for sound and crowned teeth, respectively. Statistically significant differences were observed for all parameters except for CAL and for the BANA test. It may be concluded that, with the methods used in the present study, crowns may be associated with more signs of inflammation, however not with periodontal breakdown.

Descriptors: Periodontal diseases; Tooth crown; Periodontics; Prosthodontics.

Resumo: O objetivo deste estudo foi avaliar retrospectivamente as condições periodontais de pacientes com coroas fixas colocadas de 3 a 5 anos antes da realização da pesquisa. Quarenta indivíduos foram rechamados. Exames clínicos de toda a boca foram realizados avaliando-se Índice de Placa Visível (IPV), Índice de Sangramento Gengival (ISG), Profundidade de Sondagem (PS) e Nível Clínico de Inserção (NCI) em 6 sítios por dente. Radiografias paralelas foram obtidas e analisadas cegamente por paquímetro digital (distância do ápice à crista óssea). Testes BANA foram realizados. Um dente hígido contralateral foi considerado como controle. Valores médios foram obtidos e testes de Wilcoxon e $t$ pareado foram utilizados para comparar os sítios teste e controle. Coroas apresentaram um valor médio de IPV de 30,42\%, comparado com 49,17\% para dentes hígidos. O ISG foi de $33,33 \%$ e $26,25 \%$ para dentes com coroas e hígidos, respectivamente. A PS revelou valores de 2,30 e 2,14 mm e a análise do NCI demonstrou médias de 2,02 e 1,89 mm para dentes teste e controle, respectivamente. Os valores médios para as distâncias radiográficas foram de 12,73 e 13,67 mm, e para o teste BANA, de 67,50 e 50,00 para dentes hígidos e com coroas, respectivamente. Diferenças estatisticamente significantes foram observadas para todos os parâmetros, exceto para NCI e para o teste BANA. Pode-se concluir que, com os métodos utilizados no presente estudo, coroas podem ser associadas a mais sinais de inflamação, entretanto não com destruição periodontal.

Descritores: Doenças periodontais; Coroa dentária; Periodontia; Prostodontia. 


\section{Introduction}

Evidence from different studies points to a very close relationship between the periodontium and crowns and bridges. The vast majority of studies, however, focus on different aspects of the relationship between dental materials, surface characteristics, adaptation, etc., thus providing guidelines for the dental team..$^{2,4,12}$

Previous studies looking at this subject have suggested that crowns may frequently be a problem to the periodontium. ${ }^{15}$ At the moment these studies were performed, however, some confusion between gingival inflammation and periodontal breakdown existed, ultimately leading to misleading conclusions.

Even more recent studies evaluating the relationship between dental prostheses and the periodontium have focused mainly on inflammation and not on periodontal breakdown..$^{5,6,14,15}$ The success of a dental prosthesis, however, is only achieved if the restoration remains in place over time and without causing disease..$^{2,4,7,11,12}$ Evaluating the periodontium around prosthetic work is thus of utmost importance in clinical dentistry, especially trying to identify risk indicators for adverse events.

Evaluation of periodontal tissues may be performed concerning supragingival and subgingival plaque-related parameters. Clinically, plaque indices as well as marginal gingival inflammation relate to supragingival biofilm accumulation. Probeable pocket depth and clinical attachment level relate to the subgingival biofilm. Radiographic analysis may reveal signs of alveolar bone destruction. In order to assess microbial composition, the BANA test can be a useful tool since it demonstrates the presence of subgingival red complex bacteria (Porphyromonas gingivalis, Treponema denticola and Tannerella forsythia).9,10,16

The aim of the present study was to retrospectively evaluate clinical, radiographic and microbiological periodontal conditions of teeth with fixed crowns that had been in place from 3 and 5 years before the study was conducted as compared to sound teeth.

\section{Material and Methods Study population}

Forty individuals, 11 male $(27.5 \%)$ and $29 \mathrm{fe}-$ male $(72.5 \%)$, aged 30 to 55 years, from a group of 65 patients agreed to participate in this retrospective study after being invited by the authors. A response rate of $61.5 \%$ was achieved. Patients gave their written informed consent and the protocol was approved by the Ethical Committee of the Lutheran University of Brazil.

\section{Inclusion criteria}

To be included in the study, subjects should have one tooth with a metaloceramic crown placed at the University Clinic between 3 and 5 years prior to examination (test tooth) and a contra-lateral sound tooth (control tooth).

\section{Exclusion criteria}

Subjects with any other prostheses, needing antibiotic therapy in order to be periodontally examined, having any systemic disorder affecting the periodontium, pregnant or breast feeding were not included in the study.

\section{Development of the study}

After examining the records of patients that had crowns placed, a telephone call was given in order to invite the patients for examination. From the 40 individuals who agreed to participate, 7 pairs of incisors, 7 pairs of canines, 20 pairs or premolars and 6 pairs of molars were examined.

\section{Clinical examination}

Periodontal conditions were clinically assessed by a trained and calibrated examiner in terms of Visible Plaque Index (VPI), ${ }^{1}$ Gingival Bleeding Index (GBI), ${ }^{1}$ Probing Pocket Depth (PPD), and Clinical Attachment Level (CAL). Six sites per tooth were examined (distobuccal, midbuccal, mesiobuccal, distolingual, midlingual and mesiolingual).

VPI: Visible Plaque Index was assessed as a dichotomic evaluation of the Silness \& Löe Plaque Index, combining scores $0+1$ and $2+3 .{ }^{1}$

GBI: Gingival Bleeding Index, similarly, combined the scores $0+1$ and $2+3$ of the Löe Gingival Index. ${ }^{1}$

PPD and CAL: Probing Pocket Depth and Clinical Attachment Level were performed by a manual 
William's periodontal probe and were measured from the most apically probeable portion until the gingival margin (PPD) and to the cementum-enamel junction (CAL). Measurements were rounded to the nearest millimeter. ${ }^{10}$

The clinical location of the crown margin (whether supragingival, at the gingival margin, or subgingival) and its adaptation (whether well-fit or maladapted, according to Felton et al. $\left.{ }^{6}, 1991\right)$ were also assessed by an examiner unaware of the assessed clinical periodontal conditions. These assessments were performed considering the 6 sites per tooth.

\section{Radiographic examination}

Parallel periapical radiographs were taken with the aid of Han-Shin appliances in each test and control tooth and were automatically processed. Measurements of the distance between the apex and the bone crest were performed with the aid of a digital caliper by a calibrated examiner unaware of the clinical conditions at the mesial and distal portions.

\section{Microbiological examination}

After removal of supragingival plaque, intra-crevicular biofilm was collected with the aid of a sterile Gracey curette and processed in a BANA card during 15 minutes at a temperature of $55^{\circ} \mathrm{C}$, according to Amalfitano et al. ${ }^{3}$ (1993). Examination of the results was performed by a calibrated examiner, who did not know whether the tooth was a test or a control tooth, or what the clinical condition of the tooth was.

\section{Reliability}

All examinations were performed by an experienced periodontist except for the crown adaptation and crown margin location examination, which was performed by a prosthodontist. Concerning the clinical periodontal conditions, the periodontist was trained for VPI and GBI assessment. In relation to PPD and CAL assessment, weighed kappa was tested $( \pm 1 \mathrm{~mm})$ and revealed values of 0.85 and 0.71 , respectively.

Radiographic measurements were calibrated by duplicate analyses of 18 radiographs with one week's interval, without revealing statistically significant differences when tested by the paired sample $t$ test $(\mathrm{p}>0.05)$.

The kappa value for the BANA test analysis after double assessment with one week's interval was of 0.94 .

All reliability analyses were performed in individuals not participating in the study, but with characteristics similar to those of the ones who did participate.

\section{Statistical analysis}

Relative frequencies of VPI, GBI and BANA test in crowned and sound teeth were compared by the Wilcoxon Test. Mean values of PPD, CAL and Bone Height were calculated and compared between test and control teeth by the paired sample $t$ test. Spearman correlation coefficients were calculated between maladapted and subgingivally located crowns and the clinical, radiographic and microbiological results. Additionally, total VPI $\geq 50 \%$ and $\mathrm{GBI} \geq 30 \%$ were correlated with the clinical, radiographic and microbiological variables, by Spearman's correlation coefficient. The alpha level was set at 0.05 .

\section{Results}

The descriptive data of the characteristics of crowns in terms of margin location and fitness are described in Table 1 . The majority of the sites of the crowns $(78.3 \%)$ were considered well-fit. Concerning margin location, $37.1 \%$ of the sites were located supragingivally or at the gingival margin and $62.9 \%$ were located subgingivally.

The clinical, radiographic and microbiological parameters of the examined teeth are demonstrated in Table 2. Crowned teeth presented a lower mean value of Visible Plaque (30.42\%) as compared with sound teeth $(49.17 \%)$. Although a large variation was observed in this parameter, statistically significant difference was observed. Conversely, the Gingival Bleeding Index was higher $(33.33 \%)$ in crowned than in sound teeth $(26.25 \%)$. This difference was also statistically significant.

Mean probing depth in crowned teeth was 
Table 1 - Absolute and relative frequencies of fitness and margin location of the analyzed crowns ( $n=240$ sites).

\begin{tabular}{l|l|r|r}
\hline \multicolumn{2}{c|}{} & N & $\%$ \\
\hline \multirow{4}{*}{ Fitness } & Well-fit sites & 188 & 78.3 \\
\cline { 2 - 4 } & Maladapted sites & 52 & 21.7 \\
\cline { 2 - 4 } & Total & 240 & 100.0 \\
\hline \multirow{4}{*}{$\begin{array}{l}\text { Margin } \\
\text { location }\end{array}$} & $\begin{array}{l}\text { Supragingival or at gingival } \\
\text { margin location }\end{array}$ & 89 & 37.1 \\
\cline { 2 - 4 } & Subgingival location & 151 & 62.9 \\
\cline { 2 - 4 } & Total & 240 & 100.0 \\
\hline
\end{tabular}

Table 2 - Mean ( \pm Standard deviation) of the clinical, radiographic and microbiological parameters in crowned and sound teeth ( $n=240$ sites, 40 patients).

\begin{tabular}{|c|c|c|c|}
\hline Parameter & Crowned teeth & Sound teeth & P value \\
\hline VPI (\%) & $30.42(46.10)$ & $49.17(50.10)$ & $0.000 a$ \\
\hline GBI (\%) & $33.33(47.24)$ & 26.25 (44.09) & $0.035 a$ \\
\hline PPD (mm) & $2.30 \quad(0.99)$ & $2.14 \quad(0.86)$ & $0.008 \mathrm{~b}$ \\
\hline $\mathrm{CAL}(\mathrm{mm})$ & 2.02 (1.36) & 1.89 (2.00) & $0.30-n s b$ \\
\hline Bone Height (mm) & 12.73 (2.63) & 13.67 (2.38) & $0.000 \mathrm{~b}$ \\
\hline BANA (\%) & $67.50(47.43)$ & $50.00(50.64)$ & $0.071-\mathrm{ns} \mathrm{a}$ \\
\hline
\end{tabular}

a: Wilcoxon rank sign test. b: Paired sample $t$ test. ns: non-significant difference. VPI: Visible Plaque Index, GBI: Gingival Bleeding Index, PPD: Probing Pocket Depth, CAL: Clinical Attachment Level.

slightly larger in crowned than in sound teeth $(2.30$ versus $2.14 \mathrm{~mm}, \mathrm{p}=0.008)$. Statistically significant differences, however, were not observed in Clinical Attachment Level.

The radiographic analysis revealed that the sound teeth had more supporting bone as compared to the crowned teeth $(13.67$ and $12.73 \mathrm{~mm}$, respectively). The microbiological results revealed a mean percentage of BANA positive reactions of 67.50 in crowned and of $50.00 \%$ in sound teeth. A statistically significant difference could not be demonstrated $(\mathrm{p}=0.071)$.

Table 3 presents the correlations performed between maladapted crowns and the study parameters. All correlation coefficients were relatively low and the only statistically significant correlation was observed between maladapted crowns and clinical attachment level (0.15), meaning that maladapted crowns posi-
Table 3 - Spearman correlation coefficient between maladapted crowns and clinical, radiographic and microbiological parameters ( $n=240$ sites, 40 patients).

\begin{tabular}{l|c|c}
\hline \multicolumn{1}{c|}{ Parameter } & Spearman Correlation $\left(r_{s}\right)$ & $p$-value \\
\hline VPI & 0.004 & 0.95 \\
\hline GBI & 0.29 & 0.65 \\
\hline PPD & 0.1 & 0.12 \\
\hline CAL & 0.15 & 0.019 \\
\hline Bone Height & 0.161 & 0.16 \\
\hline BANA & 0.069 & 0.67 \\
\hline
\end{tabular}

VPI: Visible Plaque Index, GBI: Gingival Bleeding Index, PPD: Probing Pocket Depth, CAL: Clinical Attachment Level.

Table 4 - Spearman correlation coefficient between subgingivally located crowns and clinical, radiographic and microbiological parameters ( $n=240$ sites, 40 patients).

\begin{tabular}{l|c|c}
\hline \multicolumn{1}{c|}{ Parameter } & Spearman Correlation $\left(r_{s}\right)$ & $p$-value \\
\hline VPI & 0.07 & 0.25 \\
\hline GBI & 0.14 & 0.03 \\
\hline PPD & 0.11 & 0.08 \\
\hline CAL & 0.46 & 0.000 \\
\hline Bone Height & 0.14 & 0.20 \\
\hline BANA & 0.22 & 0.17 \\
\hline
\end{tabular}

VPI: Visible Plaque Index, GBI: Gingival Bleeding Index, PPD: Probing Pocket Depth, CAL: Clinical Attachment Level.

tively correlate to clinical loss of attachment.

Correlations between subgingival crowns and the study parameters were also calculated (Table 4). Positive correlations were obtained between subgingival crowns and all parameters. Statistically significant correlations, however, were observed with the gingival bleeding index $(r=0.14)$ and a higher correlation was observed with the clinical attachment level $(r=0.46)$, reinforcing the correlation between this parameter and maladaptation of the crowns, as previously demonstrated.

In order to have an idea of the role of supragingival plaque control, a dichotomization of the total VPI and total GBI of the individuals was performed. Fifty percent and thirty percent were considered as cut-off points for VPI and for GBI respectively. These were values close to the median. The only statistically significant correlation was observed between 
Table 5 - Spearman correlation coefficient between total $\mathrm{VPI} \geq 50 \%$ and clinical, radiographic and microbiological parameters ( $n=240$ sites, 40 patients).

\begin{tabular}{l|c|c}
\hline \multicolumn{1}{c|}{ Parameter } & Spearman Correlation $\left(r_{s}\right)$ & $p$-value \\
\hline PPD & 0.17 & 0.27 \\
\hline CAL & 0.07 & 0.66 \\
\hline Bone Height & 0.07 & 0.66 \\
\hline BANA & 0.08 & 0.58 \\
\hline
\end{tabular}

VPI: Visible Plaque Index, PPD: Probing Pocket Depth, CAL: Clinical Attachment Level.

GBI $\geq 30 \%$ and probing depth (PPD). VPI did not correlate with any of the clinical, radiographic or microbiological parameters assessed (Tables 5 and 6).

\section{Discussion}

The present retrospective study evaluated the periodontal conditions of teeth with ceramic crowns that had been in place for between 3 and 5 years as compared to those of sound teeth. The limitations of retrospective analyses, the slightly reduced number of individuals included and the inclusion of different types of teeth must be highlighted when interpreting our results. It has to be taken into consideration, however, that each crowned tooth was controlled by a similar sound tooth. Finding individuals with these conditions is not an easy task. Among the invited individuals, a good response rate was achieved. All the individuals that refused to participate in the study still had their crowns in place and did not want to participate in the study for reasons unrelated to satisfaction with the prostheses. It has to be kept in mind that, as the examined individuals were volunteers, it is more likely that the individuals with a higher standard of healthcare were the ones who showed up for examination.

The comparison employed in the present study (crowned versus contra-lateral sound teeth in the same individual) aimed at minimizing inter-individual differences, so that a more reliable result could be obtained. Smaller numbers of individuals are needed when intra-individual comparisons are possible. $^{2}$

The clinical examination comprised VPI, GBI, PPD and CAL assessments, which relate to peri-
Table 6 - Spearman correlation coefficient between total $\mathrm{GBI} \geq 30 \%$ and clinical, radiographic and microbiological parameters ( $n=240$ sites, 40 patients).

\begin{tabular}{l|c|c}
\hline \multicolumn{1}{c|}{ Parameter } & Spearman Correlation $\left(r_{s}\right)$ & $p$-value \\
\hline PPD & 0.36 & 0.02 \\
\hline CAL & 0.012 & 0.94 \\
\hline Bone Height & 0.24 & 0.14 \\
\hline BANA & 0.17 & 0.28 \\
\hline
\end{tabular}

GBI: Gingival Bleeding Index, PPD: Probing Pocket Depth, CAL: Clinical Attachment Level.

odontal status. VPI and GBI are considered indicators of gingival marginal health status and PPD may indicate both inflammation and destruction, especially if combined with CAL and radiographic examination. ${ }^{10}$ The microbiological examination in this study was performed by means of the BANA test. This test is a chair-side evaluation of the presence of putative periodontopathogens ( $P$. gingivalis, T. denticola and T. forsythia). ${ }^{9}$

An attempt to achieve a better reproducibility was made by having an experienced periodontist or prosthodontist as the examiner. Calibration for PPD, CAL, radiographic measurements and BANA test revealed that the examiners were reproducible, enhancing the reliability of the results.

The presence of supragingival plaque assessed in the present study revealed more plaque in sound than in crowned teeth. This was a surprising finding. The invitation for an examination in patients that had crowns placed, however, could have led to a more careful cleansing of those teeth by the patients before they came in for the consultation. Conversely, marginal inflammation detected by the GBI revealed more inflammation in crowned teeth. This parameter is more adequate to reveal the patient's oral hygiene habit, not just at the time of the examination. ${ }^{12}$ It should be stressed that, in our study, $62.90 \%$ of the crowns were placed subgingivally. This finding confirms those of previous studies. , $7,8,12,13,15$ All these reports affirmed that subgingival restorations are associated with gingival bleeding.

Concerning PPD, the present study observed higher values for crowned as compared to sound teeth (Table 2). Reitemeier et al. ${ }^{12}$ (2002) observed high- 
er PPD values in subgingivally placed restorations. The study by Valderhaug et al. ${ }^{15}$ (1993) also showed slightly greater PPD values in crowned teeth.

In relation to CAL, our results did not show more loss of attachment in crowned than in sound teeth (Table 2). Brunsvold, Lane ${ }^{4}$ (1990) and Reitemeier et al. ${ }^{12}$ (2002) found higher loss of attachment in places adjacent to maladapted restorations. Other studies $^{8}$ showed higher values of CAL in subgingivally located restorations, independently of the observed adaptation. Although showing higher values of CAL for crowned teeth, Wang et al. ${ }^{17}$ (1993) did not find statistically significant differences between crowned and sound teeth. The outstanding study of Schätzle et al..$^{13}$ (2001), that evaluated 160 patients during 26 years, did not find statistically significant differences between the study groups, similarly to the results of the present study. These results shed some light into the fact that the higher PPD and GBI values observed for crowned teeth are related to chronic inflammation due to the subgingival placement of the majority of the crowns.

Moreover, although with small differences, a consistently higher value of bone loss was observed for crowned teeth in the radiographic findings. The experimental design (retrospective) does not allow a claim of causality in this respect. The microbiological findings also revealed no differences between teeth with and without crowns. These results are in accordance with the lack of difference in the CAL values. ${ }^{9,10}$

Correlations between maladapted crowns and the clinical, radiographic and microbiological pa-

\section{References}

1. Ainamo J, Bay I. Problems and proposals for recording plaque and gingivitis. Int Dent J. 1975;25(4):229-35.

2. Al-Wahadni AM, Mansour Y, Khader Y. Periodontal response to all-ceramic crowns (IPS Empress) in general practice. Int J Dent Hyg. 2006;4(1):41-6.

3. Amalfitano J, De Filippo AB, Bretz WA, Loesche WJ. The effects of incubation length and temperature on the specificity and sensitivity of the BANA (N-benzoyl-DL-arginine-naphthylamide) test. J Periodontol. 1993;64(9):848-52.

4. Brunsvold MA, Lane JJ. The prevalence of overhanging dental restorations and their relationship to periodontal disease. J Clin Periodontol. 1990;17(2):67-72. rameters evaluated in the present study (Table 3) revealed a statistically significant correlation with CAL, a finding that corroborates those of previous studies. ${ }^{2,3,5}$ Correlations between subgingivally located crowns and the parameters evaluated revealed statistically significant values for GBI and CAL. This has been demonstrated by Valderhaug et al. ${ }^{15}$ (1993) and De Backer et al..$^{5}$ (2006).

The correlations between VPI $\geq 50 \%$ and $\mathrm{GBI} \geq 30 \%$ were significant only between the latter and PPD. This confirms the nature of PPD as a sign of inflammation and was also demonstrated by Reitemeier et al. ${ }^{12}$ (2002).

The findings of the present study are challenging both for Periodontology and Prosthodontics. If, on one hand, no differences were observed concerning periodontal destruction, on the other hand, higher degrees of inflammation were observed, especially in subgingivally located crowns. This should be kept in mind, since inflammation is related to a worse quality of oral health, leading do bleeding, redness and halitosis, which today are socially unacceptable. The retrospective design of the present study, the number and diversity of evaluated teeth, as well as the time after installation of the crowns could also account for the observed results.

\section{Conclusion}

It may be concluded, taking into consideration the design and limitations of the present study, that crowns may be associated with more signs of inflammation, although not with periodontal breakdown.

5. De Backer H, Van Maele G, De Moor N, Van den Berghe L, De Boever J. An 18-year retrospective survival study of full crowns with or without posts. Int J Prosthodont. 2006;19(2):136-42.

6. Felton DA, Kanoy BE, Bayne SC, Wirthman, GP. Effect of in vivo crown margin discrepancies on periodontal health. J Prosthet Dent. 1991;65(3):357-64.

7. Jacobs DJ, Steele JG, Wassel RW. Crowns and extra-coronal restorations: considerations when planning treatment. Br Dent J. 2002;192(5):263-7.

8. Kohal RJ, Gerds T, Strub JR. Effect of different crown contours on periodontal health in dogs. J Dent. 2003;31(6):40713. 
9. Loomer PM. Microbiological diagnostic testing in the treatment of periodontal diseases. Periodontol 2000. 2004;34:49-56.

10. Mombelli A. Clinical parameters: biological validity and clinical utility. Periodontol 2000. 2005;39:30-9.

11. Odman P, Andersson B. Procera AllCeram crowns followed for 5 to 10.5 years: a prospective clinical study. Int J Prosthodont. 2001;14(6):504-9.

12. Reitemeier B, Hansel K, Walter MH, Kastner C, Toutenburg $\mathrm{H}$. Effect of posterior crown margin placement on gingival health. J Prosthet Dent. 2002;87(2):167-72.

13. Schätzle M, Land NP, Anerud A, Boysen H, Burgin W, Loe $\mathrm{H}$. The influence of margins of restorations of the periodontal tissues over 26 years. J Clin Periodontol. 2001;28(1):57-64.
14. Sjögren G, Lantto R, Tillberg A. Clinical evaluation of allceramic crowns (Dicor) in general practice. J Prosthet Dent. 1999;81(3):277-84.

15. Valderhaug J, Ellingsen JE, Jokstad A. Oral hygiene, periodontal conditions and carious lesions in patients treated with dental bridges. A 15 -year clinical and radiographic follow-up study. J Clin Periodontol. 1993;20(7):482-9.

16. van Winkelhoff AJ, Winkel EG. Microbiological diagnostics in periodontics: biological significance and clinical validity. Periodontol 2000. 2005;39:40-52.

17. Wang HL, Burgett FG, Shyr Y. The relationship between restoration and furcation involvement on molar teeth. J Periodontol. 1993;64(4):302-5. 